\title{
Experiências afetivo-familiares de mulheres com alopecia areata
}

\author{
Emotive family-related experiences in \\ women with alopecia areata
}

\author{
Renata Bilion Ruiz PRADO' \\ Carmen Maria Bueno NEME²
}

\begin{abstract}
Resumo
Este estudo consistiu na análise da dinâmica emocional das experiências afetivas de mulheres com alopecia areata, tendo como eixo as relações de afeto mantidas com os pais e em suas relações conjugais. Foram entrevistadas cinco pacientes, atendidas no Instituto Lauro de Souza Lima, com idade entre 22 e 53 anos. O estudo baseou-se no método clínico de investigação e os dados foram obtidos mediante entrevistas semi-estruturadas. Nos depoimentos foram apontadas experiências dolorosas da relação conjugal e do adoecimento, que foram associadas a vivências traumáticas na infância. As associações realizadas pelas mulheres entre suas experiências passadas, relações conjugais, adoecimento e o impacto da doença na vida atual confirmaram os achados da literatura, e os dados encontrados puderam ser interpretados à luz das contribuições psicanalíticas. Os resultados obtidos podem contribuir para o esclarecimento de aspectos dinâmicos relacionados à alopecia areata e a outras psicodermatoses, bem como favorecer intervenções interdisciplinares e psicoterápicas mais efetivas com pacientes dermatológicos crônicos.
\end{abstract}

Unitermos: Afetividade. Alopecia. Família. Psicanálise.

\begin{abstract}
This study consisted of the analysis of the emotional dynamics of the emotional experiences of women with alopecia areata, rooted in the emotional relationship maintained with parents and in their matrimonial relationships. Five patients aged between 22 and 53 , cared for in the Lauro de Souza Lima Institute, were interviewed. The study was based on the clinical method of research and the data was obtained by means of semi-structured interviews. In their statements, painful experiences of matrimonial relations and sickness associated with traumatic experiences in childhood were reported. The associations made by women between their past experiences, matrimonial relations, sickness and the impact of the disease on life in the present, confirmed the findings of literature and the data found could be interpreted in view of the psychoanalytical contributions. The results obtained can help to clarify dynamic aspects related to alopecia areata and other psycho-dermatoses, as well as favoring interdisciplinary and psychotherapeutic interventions that are more effective with chronic dermatological patients.
\end{abstract}

Unitems: Affectivity. Alopecia. Family. Psychoanalysis.

$\cot$

1 Instituto Lauro de Souza, Divisão de Pesquisa e Ensino. Rod. Comandante João Ribeiro de Barros, Km 225/226, 17034-971, Bauru, SP, Brasil. Correspondência para/Correspondence to: R.B.R. PRADO. E-mail: <rrruiz@ilsl.br>.

2 Universidade Estadual Paulista, Departamento de Psicologia. Bauru, SP, Brasil.

Agradecimentos à Profa. Dra. Vera da Rocha Resende, do Programa de Pós-Graduação em Psicologia da UNESP, Campus de Assis, pelas contribuições durante o desenvolvimento da pesquisa. 
Entre as várias dermatoses, a alopecia areata ou pelada destaca-se por sua evolução crônica e associação com aspectos psicológicos ou psicossomáticos. As características dessa dermatose incluem perda de cabelos ou de pêlos em áreas redondas ou ovais, e não há presença de sinais inflamatórios ou de atrofia da pele. Geralmente, pode se manifestar no couro cabeludo ou na barba. Possui maior prevalência dos 20 aos 50 anos. É mais freqüente no sexo masculino, mas se desenvolve em ambos os sexos. É uma doença de evolução crônica e de fator etiológico desconhecido, embora exista uma correlação com as doenças congênitas, participação genética e imunológica, na qual se verifica infiltrado linfocitário de linfócitos T em torno dos folículos pilosos (Sampaio \& Rivitti, 2001).

A literatura destaca o estudo das dermatoses do ponto de vista psicossomático. Embora as investigações atuais sobre a alopecia areata sejam proeminentes, a abrangência do tema pode ser ricamente explorada. Na perspectiva dermatológica, o paradigma científico que concebe o ser humano em sua totalidade ainda não conquistou uma adesão universal dos profissionais. Entretanto, o conhecimento produzido contribuiu com o avanço de investigações entre as dimensões neurológicas, endócrinas, psicológicas e fisiológicas no processo de adoecimento. Na década de 1990, Castro (1991) considerou que a manifestação de distúrbios dermatológicos relaciona-se ao desenvolvimento de estados de ansiedade, estresse, tensão, medo e depressão, ponderando que a pele é um dos órgãos de expressão dos processos psíquicos. Posteriormente, Cohen (1995) constatou que a linguagem cutânea representa uma via de acesso para a expressão de conflitos, cuja ação psíquica tem sido reconhecida na alopecia areata, líquen rubro, psoríase, vitiligo, rosácea e em outras dermatoses e enfermidades.

Do ponto de vista fisiológico, a pele é um sistema integrado e órgão de imunovigilância avançado. É também constituída de ceratinócitos, células de Langerghans, células de Merkel, linfócitos residentes e células endoteliais do plexo capilar. Essas estruturas recebem informações do sistema nervoso central pelas terminações nervosas livres (Azambuja, 2000). A conexão entre a dermatologia e a psiconeuroimunologia privilegia as dimensões fisiológica, comportamental, cognitiva, afetiva, sistêmica e ecológica do funcionamento humano (Rocha, 2003). O stress tem papel significativo na gênese de várias doenças em decorrência das reações gerais e específicas de adaptação, especialmente por sua ação imunodepressora, dependendo dos modos de enfrentamento dos eventos estressores (Neme, 2005).

Para Urpe, Buggiani e Lotti (2005), há evidência clínica e experimental de que o cérebro pode influenciar tanto no surgimento de episódios dermatológicos quanto em sua cura, e os sistemas imune e endócrino são os principais responsáveis pela manifestação de sintomas dermatológicos.

No que diz respeito à alopecia areata, a medicina reconhece a presença de fatores emocionais associados à sua manifestação, apesar de sua etiologia desconhecida (Sampaio \& Rivitti, 2001). Na manifestação dessa dermatose, há uma possível atuação das vias bioquímicas, nas quais os fenômenos emocionais exercem influência por intermédio da ação de neuromediadores (Rivitti, 2005).

Do ponto de vista psicológico, os estudiosos buscam a conexão entre o funcionamento psíquico e as manifestações dermatológicas no contexto da história de vida do indivíduo. Em estudo realizado por Perini et al. (1984), tanto os pacientes com alopecia areata quanto os pertencentes aos grupos controles foram submetidos a eventos estressores. Entretanto, os autores não consideraram apenas a ocorrência concreta de acontecimentos indesejáveis no emergir da doença, pois observaram que os pacientes recordavam os traumas de maneira dolorosa, mesmo sem tê-los experienciado novamente.

A história de vida, quando pontilhada de conflitos, merece uma atenção especial dirigida à infância. A falta de contato ou o contato deficiente entre mãe e filho pode favorecer a eclosão de enfermidades de pele (Spitz, 1993). Segundo Caldera, Jará, Díaz, Martín e Rubio (1986), o estado emocional da criança portadora de alopecia areata encontra-se freqüentemente alterado, apresentando relações de afeto insustentáveis e marcadas por acontecimentos insatisfatórios. Situações tais como desmame traumático, sentimento de abandono e perda dos pais favorecem a carência afetiva materna e paterna e podem compor um quadro de "neurose de abandono" (Chalub, 1989). Portanto, cabe ressaltar a teoria de Bowlby (1998), na qual o autor descreve o desenvolvimento sadio da criança fundamentado nas 
primeiras ligações da infância, descritas como persistentes e contínuas, cuja principal "figura de apego" é representada pela pessoa que dispensa a maior parte dos cuidados maternos.

Em estudo realizado com uma criança de cinco anos, Kreisler (1999) detectou relações afetivas enfraquecidas, carência paterna e repetições de situações traumáticas. Volich (2000) observou que, em condições de rejeição materna, a criança pode perseverar em estado de agitação, sofrer de insônia ou chupar o dedo para substituir a mãe, valendo-se de auto-erotismo. Estudos recentes sobre o tema encontrados na literatura restringem-se à faixa etária adulta e, freqüentemente, deixam de abordar a história de vida e as vivências traumáticas da infância. Cabe destacar que foram confirmadas relações de influência entre a alopecia areata e vivências de traumas psicológicos em pacientes, sobretudo em situações de luto, nas quais a tentativa de eliminar ou diminuir a tensão foi realizada de maneira imprópria (Misery \& Rousset, 2001).

Estudos encontrados na literatura relacionam algumas dermatoses e certas características psicológicas, indicando a ocorrência de emoções significativas em indivíduos com alopecia areata aproximadamente doze meses antes de seu surgimento, enquanto em pacientes com psoríase ocorreu uma tendência maior para fazer reclamações ou queixas emocionais muito tempo antes. Embora possam ser identificadas características psicológicas consideradas específicas em diferentes dermatoses, existem também características comuns. Estudos realizados por Tordeurs, Poot, Janne, Reynaerti e Salamon (2001) indicam que tanto na alopecia areata quanto na psoríase as pessoas tendem a expressar as emoções, o sofrimento psicológico e o mal-estar por intermédio de reclamações somáticas.

De acordo com Doblado, Carrizosa e Hernández (2003), indivíduos com alopecia areata tendem a apresentar personalidade dependente e anti-social, com sintomas psicopatológicos mais específicos, como transtorno de adaptação, ansiedade generalizada e episódios depressivos. Para Picardi et al. (2003), a alopecia areata pode se manifestar em indivíduos que mantêm distanciamento nas relações interpessoais, com características predominantes de alexitimia, descontrole emocional e pouca habilidade para lidar com as emoções.
Estudos realizados à luz da teoria psicanalítica apontam a influência de situações traumáticas e de eventos de estresse no processo de evolução das doenças. Os eventos traumáticos são acontecimentos fortemente indesejáveis que geram perturbações psíquicas prolongadas e dependentes da combinação entre os recursos que o indivíduo possui e a intensidade da reação à experiência (Volich, 2000). Por outro lado, as reações psicofisiológicas do stress podem ser desencadeadas por eventos positivos ou negativos que rompem com a homeostase e apresentam finalidades adaptativas. O stress é definido como "estado de tensão não-específico de um ser vivo, que se manifesta por mudanças morfológicas tangíveis, em diferentes órgãos, e particularmente nas glândulas endócrinas" (Selye, 1952, p.20).

As experiências individuais configuradas como dolorosas, ameaçadoras e afetivamente empobrecidas têm como resíduos emocionais os sentimentos reprimidos. À medida que novas situações se repetem e são recordadas com sofrimento, as experiências antigas são consideradas traumáticas. Portanto, a expressão verbal facilitaria a identificação de sentimentos afetivos tanto na infância quanto na fase adulta. Para Freud (1899/1969), ao ingressar na maturidade sexual, o indivíduo pode reviver de modo traumático ou não suas experiências do passado, independentemente da similaridade concreta entre as experiências passadas e as atuais. $O$ efeito traumático depende também dos recursos disponíveis pelo indivíduo e da intensidade da reação à experiência.

A opção pelo estudo de pessoas que sofrem com a alopecia areata fundamentou-se em observações clínicas realizadas no processo psicodiagnóstico de pacientes em tratamento médico e psicológico no Instituto Lauro de Souza Lima (Bauru-SP), considerado pela Organização Mundial da Saúde um centro de referência nacional na assistência, ensino e pesquisa da hanseníase e dermatologia geral.

As observações clínicas mostraram que os componentes psicoafetivos negativos identificados na história de vida dos pacientes tinham suas raízes na infância e permaneciam até a idade adulta, mesmo após a manifestação da doença. Nos pacientes atendidos, foram freqüentemente constatados comprometi- 
mentos emocionais, tanto nas relações parentais quanto na vida conjugal, identificando-se experiências de privação afetiva, abandono, rejeição ou separação temporária. Tais observações motivaram este estudo - focalizado na expressão dos aspectos afetivos presentes na situação de doença e vivenciados de maneira subjetiva e particular - que teve como objetivo realizar a análise da dinâmica emocional de mulheres com alopecia areata, delimitando como eixo as relações de afeto com a família de origem (pais) e as relações conjugais, conforme relato de experiências das participantes.

\section{Método}

O estudo foi baseado no método clínico de investigação (Trivinos, 1995) e de natureza descritivo/ interpretativa. Respeitou-se a espontaneidade no modo de falar das participantes, estimulando o emergir de conteúdos presentes em seu imaginário. Utilizou-se a técnica da entrevista semi-estruturada, que permitiu a recuperação e exploração de fragmentos de lembranças no relato das mulheres entrevistadas, possibilitando a reconstrução das histórias de suas vidas afetivas desde a infância.

Participaram deste estudo cinco mulheres, pacientes do Instituto Lauro de Souza Lima (Bauru), sendo quatro casadas e uma viúva, com idades entre 22 e 53 anos. Apenas uma participante tinha ocupação profissional (instrutora de serviços gerais), enquanto as demais exerciam as atividades do lar, e todas residiam na cidade de Bauru (SP). A amostra foi constituída exclusivamente de mulheres, tendo em vista que os pacientes masculinos atendidos no ambulatório não dispunham de tempo para comparecer às entrevistas em horário de trabalho e apresentavam menor aderência aos tratamentos médicos e psicológicos oferecidos, comparativamente ao universo feminino. As mulheres, identificadas com nomes fictícios, foram selecionadas aleatoriamente entre as pacientes com alopecia areata que tinham ou tiveram algum tipo de relacionamento conjugal e estavam sendo atendidas na rotina do ambulatório de dermatologia da instituição onde o estudo foi realizado, na época da coleta de dados. Todas as convidadas concordaram em participar, relatando suas histórias de vida e de relacionamento conjugal.

\section{Procedimentos}

Em uma proposta de trabalho interdisciplinar, os pacientes que procuram o ambulatório, coordenado por uma médica dermatologista, são encaminhados para a equipe de psicólogos, apresentando diferentes tricoses: alopecia areata; alopecia androgenética; tricotilomania; síndrome da queda anájena, entre outras doenças. O médico investiga, faz o diagnóstico e propõe a intervenção medicamentosa e outros procedimentos terapêuticos, enquanto o trabalho da psicologia abrange o processo psicodiagnóstico interventivo e a psicoterapia, durante o tempo necessário para a repilagem dos fios de cabelo. Semanalmente, são realizadas reuniões ambulatoriais entre dermatologistas e psicólogos, com o objetivo de discutir os principais aspectos psicodermatológicos e as expectativas do paciente quanto ao diagnóstico e prognóstico, tendo em vista o prolongamento do tratamento.

As participantes foram previamente agendadas e individualmente entrevistadas, com média de três encontros, com duração máxima de 60 minutos cada entrevista. As entrevistas foram gravadas e transcritas integralmente. As respostas produzidas pelas entrevistadas apresentaram características peculiares e, em vários aspectos dos relatos, os conteúdos relatados permitiram a sua organização em categorias de experiências psicológicas.

As informações foram obtidas por meio dos relatos espontâneos das entrevistadas, com base em questões gerais iniciais colocadas pela entrevistadora para estimular os relatos. As entrevistas clínicas realizadas compuseram um processo de triagem diagnóstica interventiva, no qual foram trabalhados aspectos relacionados às expectativas negativas das pacientes frente à cura da dermatose associadas aos conflitos afetivos familiares e aos sentimentos presentes nas dificuldades conjugais. Todas as pacientes foram incluídas no processo psicoterápico após a realização das entrevistas, na rotina de atendimentos da instituição.

A entrevista foi constituída por uma questão norteadora central: "Fale-me sobre a sua vida". Com base nesta, surgiram outras questões que abarcavam fragmentos de lembranças afetivas não elaboradas e pertencentes ao contexto familiar de origem e das relações conjugais durante o relato espontâneo de cada entrevistada. 
Os relatos das entrevistadas foram mantidos em sigilo, respeitando-se o anonimato. A autorização das entrevistadas para participar deste estudo foi obtida por meio da assinatura do Termo de Consentimento Livre e Esclarecido. A pesquisa foi submetida à apreciação da Comissão Científica e do Comitê de Ética em Pesquisa da instituição e obteve parecer favorável.

\section{Análise dos dados}

Neste estudo qualitativo, o conteúdo gravado das entrevistas foi integralmente transcrito e analisado. As entrevistas visaram à obtenção de relatos de memórias dos aspectos mais marcantes das experiências afetivas das pacientes. As respostas das participantes, após a questão central norteadora, abrangeram aspectos afetivos da relação com os pais e com o cônjuge, além de aspectos da vida conjugal, adoecimento e vivências atuais, de acordo com as ênfases dadas pelas próprias participantes, e foram organizadas nos seguintes eixos temáticos: relação com os pais; namoro e casamento; sexualidade e relação conjugal; adoecimento; doença e estigma.

\section{Resultados e Discussão}

As respostas transcritas e organizadas em categorias temáticas estão apresentadas de acordo com as categorias nas quais foram inseridas.

\section{Relação com os pais}

A análise dos relatos das participantes concernentes à infância e à relação com os pais evidenciou referências afetivas mais negativas do que positivas, com indicações de vínculos inseguros ou frágeis. Ao recordarem fragmentos de suas histórias de vida associados ao relacionamento com os pais, narraram as seguintes passagens:

Como minha mãe trabalhava, tinha que fazer as coisas certinhas para não apanhardela. Euera criança também, não conseguia ter todas as responsabilidades de adulto. Ela estava semprebrava, nervosa com todo mundo. Não tive afeto, diálogo e nem pude contar meus problemas pra minha mãe ... (Sandra).

Minha mãe era muito nervosa e tinha ataque epiléptico. Morreu quando eu tinha quatro anos... Eu não aceitava a nova esposa do meu pai. Minha madrasta era ignorante... Meu pai bebia e brigava muito. A nossa convivência não era boa. Ele era severo, mas era um bom pai. Ele não sabia passar carinho, mas tinha amor pelos filhos, aquela coisa antiga eignorante (Ana).

A gente sempre teve desentendimento. Nós somos muito parecidos... Meu pai era muito pouco de abraço e beijo, mas semprenas necessidades ele estava presente... Antes desermãe, não valorizava minha mãeno papel de querer me dizer no que estava certa e no que estava errada. Nós nunca fomos de sentar e conversar (Paula).

Minha avó me ensinou a passar roupa, aprender a cozinhar. Ensinou-me aviver. Minha mãe não fez isso por mim ... Meus tios brincavam comigo ... Minha mãe não foi mãe .... Era uma carrasca, revoltada comigo, e a irmã mais velha sofria como eu ... (Irene).

Meu pai é bom, me trata bem, mas não sei se me ama. Fica agressivo quando bebe, xinga muito a minha mãe... (Hilda).

As figuras materna e paterna são concebidas negativamente: as lembranças de experiências afetivas suscitam sentimentos de frustração e vazio afetivo. A figura materna é apresentada apenas como uma pessoa que ensina e faz o bem à criança. Geralmente a mãe e/ou o pai aparecem como figuras autoritárias, oferecendo vínculos inseguros ou hostis. Nas entrelinhas, aparece uma auto-avaliação negativa e insegura associada a situações de abandono e privação, além de sentimentos de rejeição afetiva. A vivência traumática desses episódios da infância mobilizou sentimentos autodepreciativos. A provisão dos cuidados básicos essenciais ao desenvolvimento infantil parece não ter sido suficiente para garantir a manutenção da relação de troca afetiva positiva entre os pais e estas filhas.

\section{Namoro e casamento}

Todas as participantes casaram-se muito novas, com o primeiro namorado; três delas engravidaram durante o namoro, possivelmente buscando a satisfação de suas necessidades afetivas, conforme se depreende de seus relatos. A opção pelo companheiro conjugal não pareceu ter sido baseada na admiração, nas idéias românticas ou no amor, mas em uma atitude fatalista e de submissão a regras sociais, impostas e sustentadas também pelos pais. A possibilidade de uma opção consciente e afetuosa pelo parceiro mostrou-se prati- 
camente nula, constatando-se, no relato das entrevistadas, uma aceitação passiva da imposição de regras sociais pelos pais, da privação de recursos materiais e aparente indiferença quanto à infidelidade do marido. A responsabilidade individual no enfrentamento das emoções e das próprias decisões parece diluída, constatando-se uma forte tendência à vitimização e à culpabilização do outro. As entrevistadas associaram a doença a seus problemas conjugais e familiares. Ao atribuir a causa dos seus problemas ao outro, mantiveram atitude de passividade diante dos conflitos e da vida. Os depoimentos a seguir indicam uma escolha conjugal imatura ente as mulheres entrevistadas e sugerem um comportamento passivo diante das dificuldades no casamento.

Quem escolheu meu marido foi minha mãe... Prefiro aceitar a traição do meu marido do que entregar a minha casa, o nosso dinheiro nas mãos de outra mulher eseparar os filhos do pai... (Sandra).

Sou muito nervosa, principalmente depois que eu descobriquemeu marido pareceque tem uma filha com outramulher... (Paula).

Meu marido semprefoi ruim dentro de casa. Passei cinco anos como teto da casa emencerado. Elenão dá dinheiro pra comprar coisas básicas... . A pior mudança que aconteceu pra mim foi o casamento, mesmo assim prefiro ficar com meu marido... (Irene).

\section{Sexualidade e relação conjugal}

As entrevistadas narraram conteúdos negativos quanto à vivência da sexualidade no convívio conjugal: distanciamento afetivo; pouca concretização de anseios e metas de vida; manutenção de baixa auto-estima e auto-imagem prejudicada, agravadas também pela doença. A vivência da menopausa foi considerada pelas entrevistadas um processo de adoecimento, de envelhecimento inevitável e o fim da etapa reprodutiva. Os sintomas de depressão descritos associaram-se à baixa auto-estima, enaltecendo o sofrimento, o sentimento de inutilidade, enfraquecimento, dependência e inferioridade, conforme a descrição dos depoimentos que se seguem:

Eleémuito instintivo na relação sexual, eu não gosto, mas fico esperando a iniciativa dele... Também, estou entrando na menopausa... Me considero uma pessoa muito 492 doente... Me sinto inferiorizada perto das pessoas, engordei demais... Não me olho no espelho, acho que as pessoas pensam que sou feia... (Sandra).

Eu perdi o interesse por sair de casa, tenho uma tristeza profunda, dificuldades para tomar decisões, não tenho amigos, sinto muito cansaço, não gosto do meu trabalho, mas, não abandono... Sofro de depressão, insônia, ácido úrico, menopausa; perdi um pouco da minha audiçãoe visão....... Me acho feia evelha, cheia de cabelos brancos... Minha preocupação com o cabelo é não poder pintá-lo, pois acho que pode cairmais... Fico irritada, incomodada e tenho medo de perdê-lo por completo ... (Ana).

Quando nasceuminha filha, eu pus prafora o queestava tanto tempo dentro. Ficava deitada o dia inteiro, chorava muito, não queria conversar nem ver o bebê, mas fui medicada ... (Paula).

Outra condição mantenedora do comportamento passivo e da perda da libido relaciona-se à convivência com o parceiro alcoolista. Ao buscar a satisfação de suas vontades, o parceiro se mantém distante dos conflitos familiares e domésticos, e a relação com a esposa converte-se em uma díade competitiva e destrutiva. Por seu lado, as mulheres apresentam diminuição do desejo e da atividade sexual, além de dificuldades para reconstruir afetivamente sua vida conjugal. Convivem com parceiros que não desempenham satisfatoriamente os seus papéis e que, anulando-se nas decisões e tarefas familiares, manifestam-se impositivamente quando se encontram alcoolizados.

Eu era tipo Amélia e minhas filhas não eram assim, enfrentavam ele. Eu defendia elas quando ele queria bater, machucar. Eele ficava contra mim, me ofendia porque protegia elas. Não suportava ver ele bebendo... (Ana).

Quando casamos, meu marido me tratava muito mal. Tinh a medo de perder meu marido pra outra e foi o ano mais dificil, porque meus cabelos começaram a cair muito e tive que usar peruca... . Mesmo assim, prefiro ficar com meu marido. Ele me chama de tonta, ele tem o defeito que ele bebe muito.... Eu gostaria que a gente fosse mais amigos, saíssejuntos pra passear, ir em festa, saber o que acontece um com o outro, e ele não beber... (Hilda).

De modo geral, os relatos obtidos das participantes indicam o não enfrentamento direto de seus problemas e dificuldades conjugais. A sustentação do relacionamento conjugal é marcada por frustrações aparentemente recíprocas; a ausência de diálogo e de proximidade afetivo-sexual perpetua a insatisfação e 
manifesta-se no adoecimento e no enfrentamento da doença.

A sensação de fracasso pessoal, a perda da libido e do interesse pela vida, a insatisfação consigo, com o próprio corpo e a depressão são abordados no mesmo contexto dos aspectos ligados à doença que promove a queda de cabelos, confirmando a perda dos atributos femininos.

Os conflitos conjugais relatados pelas participantes podem ser considerados eventos estressores e, conseqüentemente, fatores de risco psicossomático para a doença dermatológica auto-imune em estudo. Constatou-se a manifestação de sintomas depressivos associados à baixa auto-estima, intensificados pela emergência da doença, compreendida de acordo com o significado individual e representativo que cada participante Ihe atribuía. Por exemplo, o quadro de depressão pós-parto, descrito por Paula, destaca-se entre outros episódios depressivos relatados pelas participantes. Logo após o nascimento da filha, Paula apresentou a alopecia, conjugando aspectos psicossomáticos em seu difícil processo de adaptação puerperal e em sua necessidade de extravasar sentimentos contidos. A gravidade da doença ou a intensidade da queda dos cabelos e pêlos corporais não pareceu constituir fator determinante de sua pior ou melhor aceitação e convivência com a doença.

\section{Doença e estigma}

Algumas entrevistadas relataram o envolvimento com os afazeres domésticos e familiares, ou com compromissos religiosos, como forma de lidar melhor com os aspectos da doença difíceis de enfrentar. Entretanto, todas relataram afastamento social mais ou menos intenso, indicando uma auto-estigmatização pela queda de cabelo, com o prejuízo estético implicado. Aparece a preocupação com o reconhecimento da própria identidade feminina e com a melhoria da aparência. No relato de uma das entrevistadas, a freqüência ao cabeleireiro e o uso de cabeleira postiça demonstram a necessidade de melhorar sua imagem e manter os atributos femininos perdidos com a doença, apontada no seguinte relato:

... porque meus cabelos começaram a cair muito e tive que usar peruca... . Mesmo assim prefiro ficar com meu marido (Hilda).
Tendo em vista o empobrecimento das trocas afetivas nas relações familiares, pode-se considerar a descarga de afeto no processo de adoecimento comumente encontrada nos fenômenos psicossomáticos em pacientes com alopecia areata: o sintoma físico traduz sentimentos afetivos reprimidos em situações tidas como ameaçadoras e infelizes, como é possível identificar nos seguintes relatos: Àmedida que caio cabelo, fico mais desiludida, não aceito
essa condição, e muito menos ser traída pelo marido...
(Sandra).

Eu perdi o interesse por sair de casa, tenho uma tristeza profunda. Não tenho amigos, não gosto do meu trabalho. Sofro de depressão, insônia, ácido úrico, menopausa... (Ana).

Sou muito nervosa. Tenho hipertensão, enxaqueca. Principalmente depois que eu descobrique meu marido parece que tem uma filha com outra mulher... (Paula).

Meu casamento fez com que eu tivesse derrame. Ele só é amoroso quando abraça os netos ... (Irene).

Mediante a análise qualitativa das entrevistas, buscou-se compreender e interpretar a dinâmica afetiva de cada participante assinalando o que cada uma apresentou de individual e único, mas também procurando as similaridades e o enredo comum entre elas. A releitura das falas sob a ótica psicanalítica permitiu delimitar conteúdos afetivos, tal como lembrados e relatados pelas mulheres participantes, estabelecendo-se elos entre as experiências emocionais da infância e suas atualizações na vida afetiva adulta.

Ao identificar dimensões similares nos relatos de experiências das participantes não se pretendeu estabelecer qualquer perfil psicológico das mulheres com alopecia areata, mas compreender aspectos gerais comuns em suas histórias e vivências, sem descaracterizar o único e singular apresentado em cada relato. Os conflitos vivenciados na dinâmica interpessoal das participantes desde sua infância foram considerados conteúdos latentes, traduzidos em sintomas e queixas somáticas.

A literatura psicanalítica destaca o elo entre os conflitos vivenciados na infância, que dificilmente são elaborados psiquicamente, e a vida adulta. Para Winnicott (1988, p.43), a perpetuação desses conflitos apresenta efeitos nocivos que são adversos ao corpo. 
Ele alerta: "O corpo da criança é capaz de suportar uma grande tensão, mas justamente a mesma tensão, se mantida pela vida adulta, pode eventualmente gerar situações somáticas irreversíveis".

A história de vida relacionada à infância apresentada pelas mulheres entrevistadas revelou a aridez afetiva de suas relações parentais, pontilhadas por situações emocionais traumáticas. Na vida adulta, os traumas da infância foram revividos de maneira dolorosa, na manutenção de relações conjugais insatisfatórias e difíceis. As tensões geradas por suas vivências de medo e insegurança, e a necessidade de estar sempre correspondendo às expectativas do outro, configuram sua possível suscetibilidade à fragilidade psicossomática e à doença. Algumas mulheres recordaram-se de que, na infância, assumiram responsabilidades adultas por exigência dos pais, enquanto outras se lembraram de terem sido protegidas pela mãe contra as agressões físicas do pai, com exceção de uma delas, que ficava mais exposta a tais agressões. Freud (1899/1969) observa que as manifestações somáticas podem estar presentes em indivíduos cujo afeto suscite lembranças patogênicas diante de situações repetitivas, na medida em que são rememoradas insatisfatoriamente. Por outro lado, vínculos afetivos positivos entre pais e filhos nos quais predominam o amor, a proximidade, o carinho e o contato físico favorecem o desenvolvimento psicoafetivo saudável, mesmo quando há revivências de situações traumáticas passadas.

O estabelecimento de relações sociais na fase adulta é influenciado pela relação de estabilidade entre a criança e a figura de ligação. Freud (1916/1976) descreveu que, na menina, o Complexo de Édipo é abandonado gradativamente, pois os seus desejos em relação ao pai são fortemente catexizados no inconsciente e auxiliam a prepará-la para a fase genital e a maternidade. Sua tendência sexual direta é transformada em tendências inibidas de tipo afetuoso. Contudo, observou-se que a busca pela afetividade - na relação das entrevistadas com a figura paterna - reproduziu-se na vida adulta, culminando na atual dinâmica conjugal. A expectativa era de suprir suas carências afetivas, segurança e confiança não asseguradas na relação amorosa, mas o companheiro conjugal não pôde garantir o preenchimento do vazio afetivo da esposa. O conflito de rela494 cionamento com as figuras materna e paterna, portanto, fortaleceu-se na relação afetivo-sexual com um companheiro insatisfatório. Os maridos eram percebidos, na maioria das vezes, como ausentes, e os pares pouco expressavam afeto e carinho. As esposas nutriam expectativas no casamento e tinham dificuldades no modo de conduzir os conflitos e elaborar seus sentimentos ambíguos em relação aos cônjuges.

A análise dos relatos permitiu constatar que as entrevistadas reviveram psiquicamente as experiências do passado na realidade presente, internalizando-as como negativas; ou seja, a fixação psíquica dos traumas patogênicos impediu a exteriorização e a resolução de afetos nos relacionamentos conflituosos atuais. Além de reviverem psiquicamente as experiências de afeto de maneira insatisfatória, estabeleceram uma relação causal entre os eventos do passado e os do presente ao atribuírem suas insatisfações afetivas e prejuízos na saúde aos acontecimentos passados. Essa realidade pode ser compreendida pela teoria de Freud (1916/1976) ao conceber que o indivíduo experimenta intensa reação emotiva diante de acontecimentos dolorosos que são recordados, sem libertar-se deles.

Constatou-se que o funcionamento psicológico das entrevistadas caracterizou-se pelo processo de vitimização e adoecimento. Freud (1932/1969), ao reportar-se à infância, concebeu a menina como menos auto-suficiente e mais dependente, dócil e aberta ao mundo exterior, embora equiparasse os impulsos femininos agressivos quantitativamente à violência dos meninos. Na menina, o comportamento não tem como principal característica a agressividade e a obstinação. A concepção de Freud fornece elementos teóricos para a compreensão da conduta passiva da mulher que, ao tentar garantir as trocas afetivas, sente-se incapaz de assumir desejos, necessidades e sentimentos. As entrevistadas revelaram encontrar dificuldades em expor seus afetos: permaneciam caladas, choravam e desenvolveram sintomas depressivos.

Os sintomas de depressão podem progredir no quadro de associação afetiva vazia, no qual o indivíduo pode tornar-se vulnerável à desorganização psicossomática, ao medo, à insegurança e à necessidade de corresponder à expectação do outro (Kreisler, 1999). Segundo Fried, M.A. Gupta e A.K. Gupta (2005), cerca de 30\% dos pacientes dermatológicos apresentam distúrbios psiquiátricos, e a depressão é a ocorrência mais 
comum. Esse transtorno manifesta-se com maior freqüência em períodos mais decisivos da vida do indivíduo. O diagnóstico precoce e o tratamento da depressão podem evitar conseqüências catastróficas, principalmente o suicídio. As alterações cutâneas apresentadas pelas mulheres deste estudo foram associadas a prejuízos estéticos e ao envelhecimento cronológico. Conseqüentemente, as implicações psicossociais revelaram-se tanto nos convívios social, sexual e familiar, quanto no prazer em realizar atividades de interesse pessoal.

Uma das entrevistadas relatou ter sofrido de um quadro de depressão pós-parto, caracterizado por desânimo, choro e rejeição ao bebê. Segundo Moraes et al. (2006), esse transtorno é atualmente considerado um problema de saúde pública, por sua alta freqüência e conseqüências. É influenciado por dificuldades socioeconômicas da puérpera e rejeição à maternidade, podendo ocorrer mesmo sem a existência de problemas psiquiátricos anteriores à gestação.

Sinais de depressão podem estar presentes também na meia-idade e são descritos como nervosismo, irritabilidade, diminuição do interesse sexual e tristeza, sintomas também destacados pelas participantes deste estudo. Entretanto, do ponto de vista psicossocial, o período da meia-idade pode ser caracterizado como uma vivência de crescimento pessoal, enriquecida pelo compartilhamento de experiências em contexto sociocultural semelhante e pela resignificação da vida nesta etapa do desenvolvimento (Mori \& Coelho, 2004). É possível, portanto, tornar a vivência da meia-idade um momento de vida menos sofrido e mais inventivo, levando em consideração as questões singulares e as maneiras individuais de lidar com esse novo momento.

Os relatos obtidos das mulheres que participaram deste estudo revelaram profundas relações de significado entre os danos emocionais e afetivos vividos na infância e sua revivência nas relações conjugais e no adoecimento. Parte desses danos pode ser compreendida como fonte interna de estresse crônico, que gera alterações inevitáveis no sistema imunológico, visto como o sistema de defesa e de identidade (Neme, 2005).

Breuer e Freud (1893/1974) admitiram que na relação simbólica entre psique e soma existe uma associação entre episódios de trauma, de emoção e de sintomatologia física, nos quais o indivíduo vivencia uma história de sofrimento. Freud (1895/1969) apontou que as experiências afetivas podem ser representadas pela dor ou satisfação. Nas manifestações somáticas, o sentimento afetivo pode rememorar e intensificar as representações mentais, ou seja, produzir lembranças patogênicas. A memória do indivíduo é constituída por lembranças encobridoras, representadas por reminiscências fragmentadas e isoladas. Em estudo realizado por Perini et al. (1984), verificou-se que os pacientes de alopecia areata vivenciavam eventos estressores e que a recordação de traumas era intensamente dolorosa e mais expressiva, em comparação à ocorrência de acontecimentos indesejáveis.

Segundo Volich (2000), a psicossomática do adulto é investigada com maior rigor quando embasada na compreensão da psicossomática da criança. As experiências afetivas relacionadas ao processo de adoecimento e vivenciadas nos relacionamentos conjugais deteriorados são produtos de relações parentais que se desenvolvem em um ambiente afetivo ameaçador e desestabilizador, com empobrecimento das relações. Acontecimentos desagradáveis do passado são apontados como motivos para o surgimento da doença, e a passividade diante da tomada de decisões pode ser vista como estratégia para obter afeto, ditada pela sobrecarga de responsabilidades (Prado, 2002). A aderência aos eventos do passado é vivenciada patologicamente, ou seja, há uma fixação nos traumas emocionais. Reações emocionais intensas são evocadas com as lembranças dolorosas, reavivadas por experiências e relações afetivas atuais.

A abordagem psicanalítica em psicossomática, especialmente em psicodermatologia, permite estabelecer conexões entre a psicologia e a dermatologia, constituindo possibilidades de compreensão das doenças dermatológicas, nas quais a pele é vista como o primeiro meio de contato entre o indivíduo, o outro e o mundo, além de uma das mais importantes vias por meio das quais os conflitos afetivos e as emoções podem ser expressos.

\section{Considerações Finais}

Os depoimentos referidos pelas mulheres participantes deste estudo revelaram uma trajetória de 
sofrimento nas relações conjugais, repetindo suas histórias de vida, permeadas desde a infância por experiências traumáticas e por insegurança nos vínculos afetivos. A abordagem psicanalítica permitiu a compreensão da singularidade das experiências emocionais presentes nos relatos e a identificação de aspectos vivenciais comuns às cinco entrevistadas, no que se refere ao conteúdo dos depoimentos referentes à sua história de vida.

Os resultados obtidos, nos aspectos similares e singulares analisados, corroboram os encontrados na literatura da área, e podem servir de base para outros estudos que visem o estabelecimento de novas interpretações e relações em pacientes com alopecia areata ou com outras patologias. Sugere-se a realização de estudos com maior número de participantes e de investigações clínicas com outras díades que permitam estabelecer comparações com os resultados obtidos neste trabalho, trazendo contribuições ao campo das psicoterapias nos casos de pacientes com alopecia areata e outras psicodermatoses, em contexto privado ou institucional público. Estudos desta natureza podem resultar em contribuições teóricas à abordagem psicodinâmica de psicodermatoses e outras manifestações psicossomáticas.

Considerando-se os limites deste trabalho, sugere-se a realização de investigações que permitam clarificar os aspectos comuns e particulares encontrados no relato das experiências emocionais passadas e atuais das participantes visando fortalecer parcerias com o tratamento médico de doentes com alopecia areata e diminuir o sofrimento frente a uma doença crônica que tanto interfere no bem-estar e qualidade de vida destes pacientes. Nesta abordagem, não apenas o paciente poderá ser beneficiado, mas também os familiares, que devem ser inseridos no processo de tratamento.

Os aspectos psicológicos discutidos neste estudo podem auxiliar o trabalho de investigação diagnóstica realizado por psicólogos em procedimentos de triagem em instituições de saúde, clarificando indicações de psicoterapia e/ou outras intervenções terapêuticas para pacientes com diagnóstico de alopecia areata. A formulação de programas de atendimento que incluam intervenções junto à família pode trazer melhorias às relações afetivas atuais, reduzindo a repetição de padrões afetivos traumáticos ou novas fontes de estresse que interfiram negativamente nos tratamentos, tanto em mulheres como em homens com esta doença crônica.

\section{Referências}

Azambuja, R. D. (2000). Dermatologia integrativa: a pele em novo contexto. Anais Brasileiros de Dermatologia, 75 (4), 393-420.

Bowlby, J. (1998). Perda. São Paulo: Martins Fontes.

Breuer, J., \& Freud, S. (1974). Estudos sobre a histeria. In J. Strachey (Ed.), Edição standard brasileira das obras psicológicas completas de Sigmund Freud (Vol.2, pp.13-39; 256-269). Rio de Janeiro: Imago. (Originalmente publicado em 1893)

Caldera, M. T., Jará, C., Díaz, M. C., Martín, A. M., \& Rubio, S. (1986). Alopecia areata em uma perspectiva psicossomática. Boletín Hospitalar San Juan de Dios, 33 (6), 393-399

Castro, M. G. C. (1991). Uma abordagem alternativa: terapêutica tópica. Anais Brasileiros de Dermatologia, 66 (4), 161-162.

Chalub, E. C. C. (1989). Síndrome de carência afetiva com manifestação da pele: relato de um caso clínico. Informação Psiquiátrica, 8 (1), 27-30.

Cohen, B. A. (1995). Atlas colorido de dermatologia pediátrica. São Paulo: Manole.

Doblado, S. R., Carrizosa, A., \& Hernández, M. J. G. (2003). Alopecia areata psychiatric comorbidity and adjusment to illness. International Journal of Dermatology, 42 (6), 434-437.

Freud, S. (1969). Conferência XXXIII: a feminilidade. In J. Strachey (Ed.), Edição standard brasileira das obras psicológicas completas de Sigmund Freud (Vol. 22, pp.139-165). Rio de Janeiro: Imago. (Originalmente publicado em 1932).

Freud, S. (1969). Lembranças encobridoras. In J. Strachey (Ed.), Edição standard brasileira das obras psicológicas completas de Sigmund Freud (Vol. 3, pp.329-354). Rio de Janeiro: Imago. (Originalmente publicado em 1899).

Freud, S. (1969). Projeto para uma psicologia científica: afetos e estados de desejos. In J. Strachey (Ed.), Edição standard brasileira das obras psicológicas completas de Sigmund Freud (Vol. 1, pp.381•453). Rio de Janeiro: Imago. (Originalmente publicado em 1895).

Freud, S. (1976). Conferência XVII: o sentido dos sintomas. In J. Strachey (Ed.), Edição standard brasileira das obras psicológicas completas de Sigmund Freud (Vol. 17, pp.305-322). Rio de Janeiro: Imago. (Originalmente publicado em 1916).

Fried, R. G., Gupta M. A., \& Gupta, A. K. (2005). Depression and skin disease. Dermatologic Clinics, 23 (4), 657-664.

Kreisler, L. (1999). A nova criança da desordem psicossomática. São Paulo: Casa do Psicólogo. 
Misery, L., \& Rousset, H. L. (2001). Pelade est-elle une maldiepsychosomatique? La Revue de Médecine Interne, $22(3), 274-279$

Moraes, I. G. S., Pinheiro, R. T., Silva, R. A., Horta, B. L., Sousa, P. L. R., \& Faria, A. D. (2006). Prevalência da depressão pós-parto e fatores associados. Revista Saúde Pública, 40 (1), 177-187.

Mori, M. E., \& Coelho, V. L. D. (2004). Mulheres de corpo e alma: aspectos biopsicossociais da meia-idade feminina. Psicologia: Reflexão e Crítica, 17 (2), 177-187.

Neme, C. M. B. (2005). Stress, enfrentamento e resiliência na história de mulheres com e sem câncer. Laboratório de Estudos Psicofisiológicos do Stress. Campinas: Universidade Estadual de Campinas.

Perini, G. I., Veller Fornasa, C. V., Cipriani, R., Bettin, A., Zecchino, F., \& Peserico, A. (1984). Life events and alopecia areata. Psychotherapy and Psychosomatics, 41 (1), 48-52.

Picardi, A., Pasquini, P., Cattaruzza, M. S., Gaetano, P., Balina, G., Melchi, C. F., et al. (2003). Psychosomatic factors in first-one alopecia areata. Psychosomatics, 44 (5), 374381.

Prado, R. B. R. (2002). Análise de aspectos afetivo-familiares de mulheres portadoras de alopecia areata. Assis: Faculdade de Ciências e Letras, Universidade Estadual Paulista.

Rivitti, E. A. (2005). Alopecia areata: revisão e atualização. Anais Brasileiros de Dermatologia, 80 (1), 619-624.

Rocha, T. N. (2003). O atendimento dermatológico integrativo: uma contextualização do atendimento médico sob a ótica integrativa. Anais Brasileiros de Dermatologia, 78 (5), 619-624.

Sampaio, S. A. P., \& Riviti, E. A. (2001). Dermatologia. São Paulo: Artes Médicas.

Selye, H. (1952). The story of the adaptation syndrome told in the formo of informal, illustrated lectures. Montreal: Acta Inc.

Spitz, R. A. (1993). O primeiro ano de vida. São Paulo: Martins Fontes.

Tordeurs, D., Poot, F., Janne, P., Reynaerti, C., \& Salamon, V. (2001). Psychological approach to different skin diseases: life events and tendency to conplain. Annales de Dermatologie et de Venerologie, 128 (1), 21-24.

Trivinos, A. N. S. (1995). Introdução à pesquisa em ciências sociais: a pesquisa qualitativa em educação: o positivismo, a fenomenologia, o marxismo. São Paulo: Atlas.

Urpe, M., Buggiani, G., \& Lotti, T. (2005). Stress and psychoneuroimmunologic factors in dermatology. Dermatologic Clinics, 23 (4), 609-617.

Volich, R. M. (2000). Psicossomática: clínica psicanalítica. São Paulo: Casa do Psicólogo.

Winnicott, D. W. (1988). Natureza humana. Rio de Janeiro: Imago.

Recebido em: 27/7/2006

Versão final reapresentada em: 15/12/2007

Aprovado em: 29/1/2008 